\title{
ПРИСТРІЙ ДЛЯ ЕКСПЕРЕС-МЕТРІЇ НІТРАТІВ У ПРОТОЧНІЙ ВОДІ
}

\author{
Салівон О. Ю., Зубчук В. І., к.т.н., доц. каф. БМІ \\ okssalivon@gmail.com,grany@meta.ua \\ Факультет біомедичної інженерії \\ Національний технічний університет Укріїни \\ «Київський політехнічний інститут ім. Ігоря Сікорського», \\ Київ, Україна \\ Таранов В. В., с.н.с \\ lambit@ukr.net \\ Інститут колоїдної хімії та хімії води ім. А. В. Думанського НАНУ \\ Київ, Україна
}

\begin{abstract}
Реферат - Методи та інструменти для визначення рівня забруднень у питній воді є важливими в різних сферах діяльності людини, адже якість води важлива завжди. Автоматизований моніторинг може покращити рівень контролю якості води. Розроблений метод та пристрій для експрес-метрії рівня нітратів у водних розчинах на основі спектрофотометричного методу. Відмінною рисою розробки є визначення забруднення для проточної води без спеціальної підготовки розчинів. Запропонований спосіб реалізовано шляхом вимірювання пропускання світлових променів через запатентовану проточну кювету в ультрафіолетовому діапазоні на трьох довжинах хвиль та математичної обробки отриманих значень за спеціально розробленим для приладу алгоритмом.

Для обробки вимірюваного результату значення пропускання променів через проточну кювету розроблено спеціальний алгоритм. Аналіз площ під кривими залежностей оптичної ділянки від довжини хвилі передбачає, щэо найбільш оптимальна довжина хвилі для оичінки характеристик концентраиії нітратів знаходиться в області 307-309 нм. Вибір аналізу трьох довжин хвиль замість одного дозволяє враховувати інші домішки та робить пристрій більш точним. Реєстрація $\mathrm{NO}_{3}$ у проточній воді здійснюється на комп'ютері з зазначенням дати та часу проведення дослідження. Успішне поєднання сучасної елементної бази, а саме напівпровідникових ультрафіолетовых випромінювачів (світлодіодів на спектральній площині від 265 до 365 нм) дозволило зменщити похибки, пов'язані з забруднювачами води з фульвокислотами. Тестування на визначення нітратів у воді дозволило провести лабораторні випробування та обгрунтувати можливість промислового використання. Запропонований спосіб реалізується шляхом вимірювання передачі світлових пучків через проточну кювету в діапазоні ультрафіолетових випромінювань на трьох довжинах хвиль з математичною обробкою значень, отриманих для спеціально розробленого приладу. Налаштовуючи прилад на допустимі домішки різних забруднювачів, ми вперше вирішуємо питання швидкого вимірювання забруднювачів безпосередньо в трубопроводі з передачею даних на віддалений комп'ютер для обробки та збереження даних про стан води протягом тривалого часу.
\end{abstract}

Ключові слова - нітрат-іони; вимірювання нітратів; проточна вода; спектрофотометрія; УФ-випромінювання.

\section{I. Вступ}

Визначення рівня забруднення питної води є важливими в різних сферах діяльності людини: екологія, хімія, медицина, ветеринарна медицина, харчова промисловість, рослинництво та тваринництва, тощо. Вода відіграє ключову роль у всіх цих областях [1].

Сьогодні дедалі більше уваги приділяється якості питної води. Встановлено, що для нормальної роботи організму необхідно використовувати достатню кількість звичайної води. Вода повинна допомогти очистити наше тіло, а не забруднювати його. Якість води визначається комплексом ii хімічних, біологічних компонентів та фізичних властивостей, які ви- значають придатність води для використання для різних цілей $[2,3]$.

Хімічні параметри якості води включають активну реакцію $(\mathrm{pH})$, окиснення, наявність азотних сполук, розчинених газів, сухих залишків, жорсткості, лужності, хлоридів, сульфатів, заліза, марганцю, а також специфічних забруднювачів, радіонуклідів, важких металів. Нітрати - це солі азотної кислоти, які є постійними складовими природних вод, максимальна допустима концентрація іонів нітрату становить 45 мг/л [4]. Якщо концентрація іонів нітрату у питній воді перевищує 45 мг/л, споживання такої води становить серйозну загрозу для здоров'я людини. Азотні з'єднання 
(сполуки нітритів та нітратів, іони амонію) утворюються, головним чином, внаслідок розкладу сечовини та білкових сполук, що надходять у воду з побутовими стічними водами, а також з содою, коксом, азотно-олов'яними водами та деякими рослинами [5].

Для визначення нітратів використовуються фотометричні, флюориметричні, потенціометричні, хемілюмінесцентні та інші методи. Найпоширенішим способом визначення концентрації нітратів у воді $€$ фотометричний метод із саліцилатом натрію в середовищі концентрованої сульфатної кислоти. Пристрої на основі дейтерієвих ламп використовують потужні джерела живлення, габаритну металеву конструкцію (вага пристрою досягає 70 кг, довжина - до 1 м).

Сучасні промислові вимірювачі використовують випромінювачі на двох хвилях і забезпечують високу швидкість вимірювань. Так, наприклад, європейська та американська, найбільш популярна фірма НАСН, визначають присутність нітратів у воді. Однак вони були розроблені раніше і працюють на трубчастому джерелі випромінювання та комплексній фільтраційній системі. Використання таких вимірювальних приладів обумовлює високу вартість пристроїв, яка досягає 20 тисяч доларів, що значно перевищує вартість самої системи очищення. Вони використовуються лише як вимірювальні прилади у великих будівлях. Отже, існує потреба в розробці та виробництві вітчизняного лічильника, який дозволить оперативно контролювати воду в реальному часі [2].

У якості основи для розробки ми прийняли метод визначення нітратів у питній воді методом тривимірної фотометрії в ультрафіолетовій системі. Важко знайти щось принципово нове у визначенні компонентів води. Увага зосереджена на простоті використання відповідно до світових тенденцій розвитку обладнання для вимірювання хімічних та фізичних показників. Портативність, відсутність допоміжних матеріалів, швидкість, точність, простота використання - ці якості повинні бути ключем до розробки пристрою зараз. Ми пропонуємо пристрій, що працює в реальному чаci, не вимагає реагентів і має достатню точність вимірювання.

\section{II. Концепція експрес-метрії нітратів}

Спектрофотометрія передбачає вибіркову взаємодію світлового випромінювання на пев- них довжинах хвиль 3 компонентами водного розчину. Наше завдання - визначити необхідну довжину хвилі, щоб максимально точно визначити концентрацію нітратів у воді 3 мінімальною похибкою, обумовленою іншими компонентами. Наступним кроком роботи є розробка схеми пристрою, яка може бути реалізована в реальних умовах 3 доступними компонентами [4].

Основна площа поглинання сполуки $\mathrm{NO}_{3}$ знаходиться в діапазоні 210...240 нм, саме ця площа використовувалася раніше для вимірювання нітратів у воді [6]. Але це з'єднання має ще іншу ділянку 304-315 нм (рис. 1), з якою нові випромінювачі добре узгоджуються. На рис. 1 наведені дані вимірювань, які ми отримали для різних концентрацій нітратів в цій області (символи для концентрацій представлені на графіку: 1-8 мг/л; 2-20 мг/л; 3-40 мг/л, 4-60 мг/л, 5-80 мг/л, 6-100 мг/л, 7-300 мг/л).

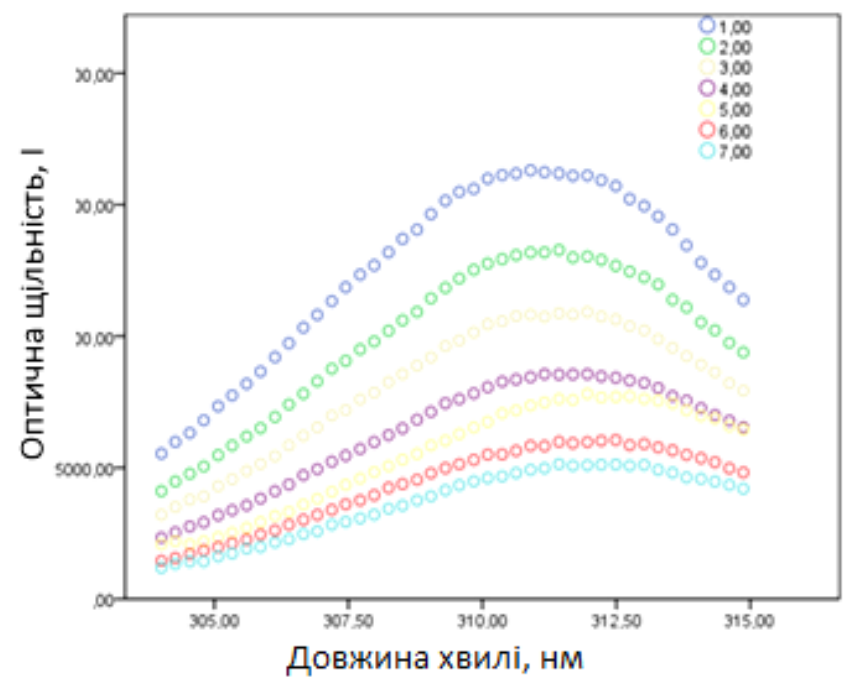

Puc. 1. Графік оптичного поглинання води 3 домішками з різними довжинами хвилі для розчинів різної концентрації: 1-8 мг/л; 2-20 мг/л; 3-40 мг/л, 4-60 мг/л, 5-80 мг/л, 6-100 мг/л, 7-300 мг/л

Для експерименту використовувався світловипромінюючий діод потужністю 2 мВт. Проведено ряд експериментів, результати яких підтверджують працездатність методу спектрофотометрії при вимірюванні рівня нітратів у воді [2].

Результати вимірювання домішок нітратів у воді представлені на графіку. У водопровідній воді водний розчин $\mathrm{KNO}_{3}$ вводили, поступово збільшуючи концентрацію. Після кожної зміни стану води проводилися вимірювання.

Результати вимірювання були отримані, коли стан дистильованої води змінився завдяки додаванню $2 \mathrm{~cm}^{3}$ розчину $\mathrm{NO}_{3}$ (з концент- 
рацією 1 мг/л) до кювети об'ємом $18 \mathrm{~cm}^{3}$. На графіках рис. 1 показана область випромінювання світлодіода, в якому знаходиться другий максимум поглинання нітратів. Зміна поглинання розчинів нітратів у воді 3 довжиною хвилі 305-314 нм доводить можливість реєстрації змін у їх концентраціях від 10 до 300 мг/л протягом не більше 0,1 секунд [1].

Таким чином, навіть 3 точністю до 10 одиниць (за шкалою вимірювача) вибіркова чутливість методу в області 305-315 нм становить не менше 0,15 мг на літр. Це забезпечує визначати наявність нітратів у діапазоні від 50 до 300 мг на літр води. Подальша математична обробка результатів вимірювань дозволить лише збільшити роздільну здатність, необхідну для реєстрації реальної води з присутністю фульвокислот та інших добавок, які впливають на результат вимірювання в цій області спектра [7]. Виходячи 3 результатів обробки вимірювань в спектральній області, де узгоджуються спектри поглинання нітратів та джерела випромінювання, визначаються найцікавіші довжини хвиль і довжина хвиль для калібрування приладу.

Розроблений найбільш зручний алгоритм та його програмування для автоматичного визначення концентрації нітратів у воді при іiі поточному дослідженні. Оціночний час вимірювання та доставка результату на віддалений комп'ютер не більше $1 \mathrm{c}$.

\section{III. Структура системи моніторингу нітратів}

Експрес-метрична схема системи контролю забрудненості води складається з блоку світлових випромінювачів, детекторів світла, блоку передачі даних, програмного забезпечення та вихідного екрану. На цьому етапі під час експериментів ми використовуємо підключення до персонального комп'ютера для збору, обробки та аналізу вимірів. У майбутньому передбачається можливість переносного функціонування пристрою. Блок-схема системи для вимірювання рівня забруднення стічної води наведена на рисунку 2.

Основними блоками пристрою $є$ блок енергоживлення, блок вимірювань, блок передачі даних, блок обробки даних, блок для відображення та реєстрації. Основними елементами блоку вимірювання є оптичний вимірювальний пристрій, блок радіатора, напівпровідниковий емітер, камера $з$ водою, приймач ви- промінювання, відповідне програмне забезпечення та блок реєстрації. Блок вимірювання використовує фотодіод з чутливістю до світла $10^{-5} \mathrm{~A} / \mathrm{B}$ і обробкою $з$ 10-розрядним АЦП.

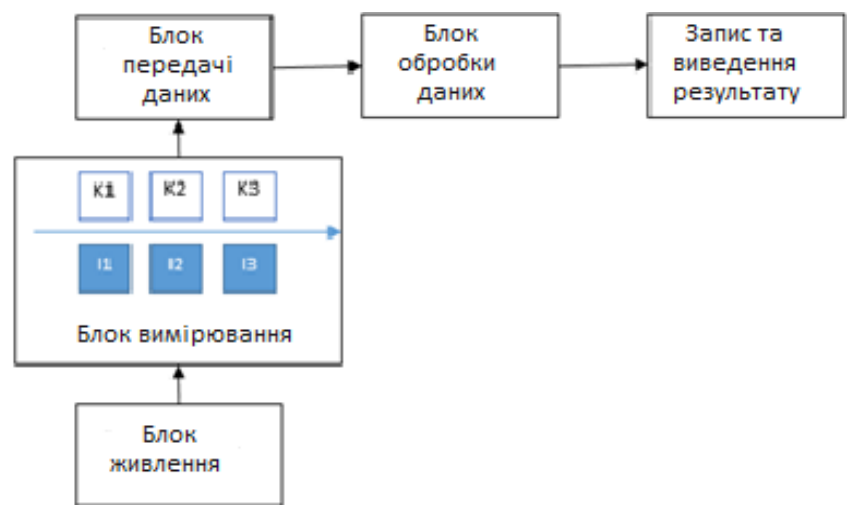

Puc. 2. Блок-схема пристрою для моніторингу нітратів у воді

Запропоновано функціональну схему експрес-метрії для системи управління потоком рідких середовищ. При розробці експериментальної зразка лічильника використовувався напівпровідниковий емітер, а для прийому випромінювання - напівпровідниковий діод, який працює у зоні UF, а замість раніше використовуваних фотопомножувачів. Обробка аналогової інформації виконується багаторозрядним АЦП, що забезпечує діапазон вимірювань в області поглинання випромінювання більше 60 дБ.

Для тестування методу обрано солі $\mathrm{NO}_{3}$. Його основний діапазон поглинання знаходиться в інтервалі 210...240 нм і раніше використовувався для вимірювання нітратів у воді [8]. Але ця сполука має ще одну ділянку 305-315 нм, 3 якою нові випромінювачі добре узгоджуються [11]. Повторне вимірювання потужності випромінювання у часі 1с забезпечує експрес вимірювання води в системах очистки води. Реєстрація значень $\mathrm{NO}_{3}$ у проточній воді здійснюється на комп'ютері 3 датою та часом вимірювання.

\section{IV. Метод визначення концентрації}

Після визначення довжин хвиль, на якій доцільно проводити вимірювання, важливо розробити алгоритм обчислення концентрації речовини на основі вимірювань оптичної густини.

Аналіз площ під кривими залежності оптичної ділянки від довжини хвилі передбачає, що найбільш оптимальна довжина хвилі для оцінки характеристик концентрації нітратів знаходиться в області 305-314 нм, тому для 
нашого методу ми обрали 310 нм з цього діапазону як одну $з$ трьох довжин хвиль. Дельтахвиля 1 нм, інтенсивність світла 2 мВт.

Концепція нашого методу грунтується на вимірюванні оптичної щільності для трьох довжин хвиль та подальшого розрахунку значень умовних одиниць вимірювального пристрою. Вибір аналізу трьох довжин хвиль замість однієї дозволяє враховувати інші домішки та робить пристрій більш точним. Вирішено провести розрахунок за методом, який у звичайному розумінні називається методом розрахунку площ.

Для визначення області ми можемо використати отримані нами дані в результаті вимірювань: I - оптична щільність і відомі довжини хвиль W (285, 310 і 346 нм). Якщо розглядати ці два масиви даних як координатну площину з першою координатою $\mathrm{W}$ та другим I, то ми можемо використовувати добре відомі формули для обчислення площі трикутника (1), де $x_{i}$ та $y_{j} \in$ координатами точок, у цьому випадку, довжини хвилі та виміряну оптичну густину.

$$
\begin{aligned}
S= & \frac{1}{2}\left(\left(x_{1} y_{2}+x_{2} y_{3}+x_{3} y_{1}\right)-\right. \\
& \left.-\left(y_{1} x_{2}+y_{2} x_{3}+y_{3} x_{1}\right)\right)
\end{aligned}
$$

Ми встановили, що існує зв'язок між фактичними значеннями концентрації та обчисленою площею отриманим графіком. Використання цієї залежності дає можливість розробити більш точний алгоритм роботи вимірювального приладу. Виходячи з результатів обробки вимірювань в спектральній області, де контури кореляції нітратів та джерела випромінювання точно узгоджуються, ми визначаємо довжини хвиль для калібрування приладу. Результати досліджень концентрацій нітратів у реальних модельних рішеннях наведені в таблиці 1.

\begin{tabular}{|c|c|c|}
\hline $\begin{array}{c}\text { Теоретичне } \\
\text { значення } \\
\text { концентрації, мг/л }\end{array}$ & $\begin{array}{c}\text { Визначена } \\
\text { концентрація, } \\
\text { мг/л } \\
\end{array}$ & $\begin{array}{c}\text { Відносна } \\
\text { похибка } \\
\text { вимірювання, \% } \\
\end{array}$ \\
\hline 12,5 & 13,7 & 9,6 \\
\hline 64,0 & 59,4 & 7,1 \\
\hline 85,0 & 80,3 & 5,5 \\
\hline 95,0 & 89,9 & 5,3 \\
\hline 110,0 & 112,3 & 2,1 \\
\hline 370,0 & 375,2 & 1,4 \\
\hline
\end{tabular}

Таблиця 1. Визначення концентрацій методом площ

Ці значення отримуються в ході експериментів $з$ водними розчинами, імітованими на основі реальної водопровідної води з набором всіх значущих елементів води та додаванням до них концентрацій нітратів. У першому стовпчику таблиці вказуються лабораторні зна- чення концентрації підготовлених модельних рішень, а другому - значення, отримані на нашому пристрої за допомогою розробленої математичної моделі.

Наступні математичні розрахунки з використанням конкретної області дозволяють побудувати графік для калібрування (рис. 3).

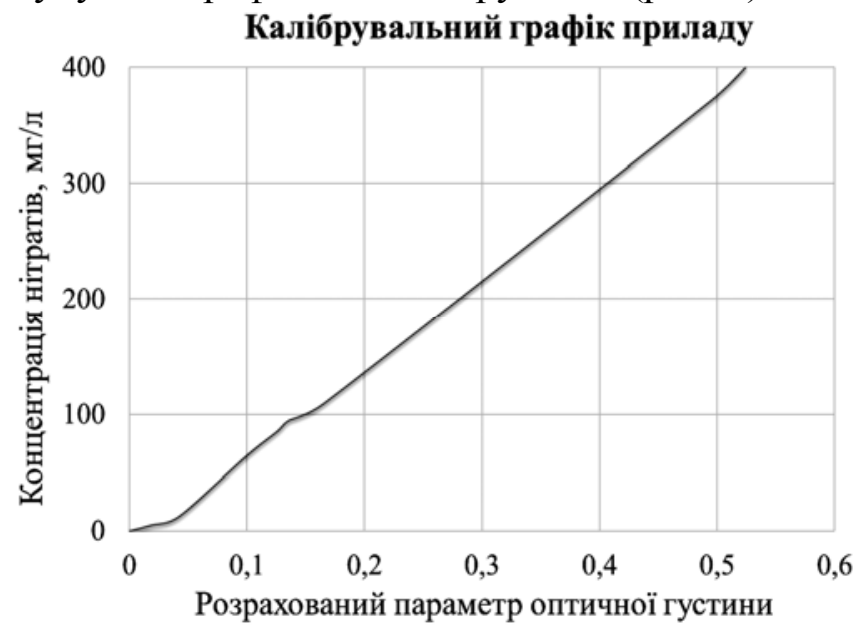

Рuc. 3. Калібрувальний графік пристрою

Вводячи різницю в області від ділянки оптичної густини для дистильованої води та вимірюваного розрахунку, помноженого на коефіцієнт коригування довжини хвилі, як фактор алгоритму обробки вхідної інформації, ми отримуємо в динамічному режимі вимірювання фактичні значення вмісту нітратів у воді.

Ось абсцис - розрахунковий узагальнений параметр, який залежить від трьох точок. Це індекс поглинання, отриманий в результаті математичної обробки.

Як на рисунку, так і за даними таблиці, очевидно, що при концентраціях понад 10 мг/л похибка не перевищує $10 \%$, а графік близький до лінійної форми. Значення відносної похибки зменшилось в порівнянні з попередніми результатами, де квадратурний метод не використовувався [11].

Використання сучасної елементної бази на основі напівпровідникових випромінювачів та приймачів $з$ наступною обробкою багатобітових АЦП - вже сьогодні забезпечує вимірювання нітратів в діапазоні від 5 мг/л до 1000 мг/л [10]. Використання джерел випромінювання в доступному для цього спектральному діапазоні від 300 до 1100 нм забезпечує експрес-метрологію для різної кількості домішок у рідких середовищах, а також створює можливість виготовлення вимірювачів, у тому числі для фармацевтичної промисловості, в системах контролю за переливанням крові та в ряді інших технологічних процесів [4]. 
Результати реєстрації сполук $\mathrm{NO}_{3}$ в проточній воді фіксуються на комп'ютері з зазначенням дати та часу дослідження. Успішне поєднання сучасної елементної бази, а саме напівпровідникових ультрафіолетових випромінювачів - світлодіодів на спектральній площині від 285 до 365 нм, дозволило зменшити похибки, пов'язані 3 забруднюванням води фульвокислотами, що заважало надійним вимірюванням. Тестування на визначення нітратів у воді дозволило провести лабораторні випробування та підійти до промислового використання [3].

\section{V. Результати та обговорення}

Сучасний прилад розроблений на основі ультрафіолетового випромінювача дейтерійної лампи і працює від 220 до 400 нм з роздільною здатністю 2-4 нм, що дозволяє вимірювати концентрацію забруднювачів води - нітратів, тощо.

Саме у цьому спектральному діапазоні досягнута найбільша чутливість при вимірюванні (до 1-2 мг/л). Проведено ряд експериментів, які підтверджують це. Розміри та вартість такого зразка не дозволяють широко використовувати такі пристрої та встановлювати їх у системах моніторингу води.

Подальший розвиток сенсора був спрямований в першу чергу на зниження вартості пристрою за рахунок використання сучасних світлодіодних ультрафіолетових випромінювачів, починаючи з 285 нм, та чутливих фотодетекторів, що працюють у цьому спектральному діапазоні. Наступна область спектру, чутлива до нітратів, розташована в районі 310 нм. Перші результати свідчать про ефективність пристрою. У майбутньому потрібно підвищити точність вимірювань для малих концентрацій. Роботи були спрямовані на вироблення пілотного зразка вимірювача забруднювань в потоку в режимі реального часу, що істотно відрізняється від існуючих вітчизняних аналогів. Виготовлення прототипу та його сертифікація дозволить досягти рівня сучасних міжнародних розробок, наприклад, фірми НАСНЕ.

\section{VI. Висновки}

Отже, розроблено метод і пристрій для спектрального експрес-визначення концентрації нітратів у воді, що характерно для ультрафіолетової спектроскопії, принцип роботи реалізується на ультрафіолетових світлодіодах.
Відносна похибка вимірювання концентрації нітратів у прозорих водних розчинах та у водних розчинах з високим забрудненням не перевищує $10 \%$, що підтверджує доцільність описаного способу та пристрою.

Налаштувавши пристрій на допустимі домішки різних забруднювачів, ми вирішили проблему швидкого вимірювання забруднювачів безпосередньо в трубопроводі та передачі даних на віддалений комп'ютер для обробки та зберігання даних про стан води протягом тривалого часу. Принцип аналізу проточної води без взяття зразків та підготовки рішень робить прилад актуальним та конкурентоздатним.

Відмінними особливостями пристрою $є$ те, що водні розчини не вимагають спеціальної підготовки перед визначенням концентрації нітратів, аналіз поточної води здійснюється без спеціальних дорогих систем фільтрації і 3 високою швидкістю вимірювання. Це дозволяє віднести нашу розробку до систем експресаналізу.

\section{ПЕРЕЛІК ПОСИЛАНЬ}

[1] O. Salivon, V. Zubchuk, V. Taranov, «Express metering of nitrates in running water» Materials of the 5th International Scientific and Practical Conference "Clean Water. Fundamental, Applied and Industrial Aspects "October 26-27, 2017. Kiev, p. 193-194.

[2] O. Salivon, V. Zubchuk, V. Taranov, «Express-metry of condensed matter» Collection of scientific works for materials XLVI practical International scientific and practical conference "Application of lasers in medicine and biology" May 2527, 2017. Kharkiv, p. 152.

[3] Patent 101854 UA, MPC G01N 21/25, G01N 21/33, Method for photometric determination of nitrates in water supply sources. L. Demutskay, I. Kalinichenko; Applicant Institute of Colloid Chemistry and Water Chemistry A. Dumansky NAS of Ukraine; Published May 13, 2013 Bulletin No. 9.

[4] V. Taranov, A. Kurlyanceva, «Optical-spectral method for determining the concentration of nitrates in water» Visnyk of Lviv University. Chemical series, 2016, 57(1), p. 226-231.

[5] I. Dzhugayeva, M. Eremina Nitrates in water as a problem of life safety. Progresses of modern natural science. 2014, № 6. P. 88 .

[6] D. Yabbarova, E. Kuznetsova, "Application of spectrophotometry for water analysis" Collection of articles of the International Scientific and Practical Conference "Interaction of Science and Society: Problems and Perspectives", Ufa. 2015. p. 33-36.

[7] Patent 116728 UA, MPC G01N 33/18, G01N 21/25, G01N 21/33, 02F 103/00, Device for photometric determination of nitrate in aqueous solution / V. Honcharuk, V. Taranov; Applicant Institute of Colloid Chemistry and Water Chemistry A. Dumansky NAS of Ukraine; - № a 2014 12883. Declared October 26, .2015, Bulletin № 20; published June 12, 2017, Bulletin № 11 .

[8] Standard Methods for the Examination of Water and Wastewater. 18 ${ }^{\text {th }}$ Edn. American Public Health Association, American Water Works Association, Water Environment Federation, W., 1992. 
[9] I. Kalinichenko, "Determination of nitrates in drinking water by three-wave photometry in ultraviolet", I. Kalinichenko, L. Demutskaya. Journal of Analytical Chemistry, 2004, Vol. 59, No. 3. P. 240 - 244.

[10] V. Goncharuk, "Chemistry of water and drinking water supply problems", Worldview, 2009, No. 4. P. 18 - 27.
[11] O. Salivon, V. Zubchuk, V. Taranov, "A system for monitoring the level of pollution of reservation with nitrates", Collect. of art. of the scient. and inform. cent. "Znanie" on mat. XXXII Intern. Scient. and Pract. Conf.: "Development science in the XXI century" 1 p., Kharkov, 2018. p. 68.

\title{
ПРИБОР ДЛЯ ЭКСПРЕСС-МЕТРИИ НИТРАТОВ В ПРОТОЧНОЙ ВОДЕ
}

\author{
Саливон А. Ю., Зубчук В. И., к.т.н., доц. каф. БМИ \\ okssalivon@gmail.com, grany@meta.ua \\ Факультет Биомедицинской инженерии \\ Национальный технический университет Украины \\ «Киевский политехнический институт им. Игоря Сикорского» \\ Киев, Украина \\ Таранов В. В., с.н.с \\ lambit@ukr.net \\ Институт коллоидной химии и химии воды им. А. В. Думанского НАН Украины \\ Киев, Украина
}

\begin{abstract}
Реферат - Методы и инструменты для определения уровня загрязнений в воде важны в различных сферах деятельности человека, ведь качество воды всегда актуально. Автоматизированный мониторинг может улучшить уровень контроля качества воды. Разработан метод и устройство для экспресс-метрии уровня нитратов в водных растворах на основе спектрофотометрического метода. Отличительной особенностью разработки является определение загрязнения для проточной воды без специальной подготовки растворов. Предложенный способ реализован путем измерения светового потока через специиальную проточную кювету в ультрафиолетовом диапазоне на трех длинах волн и с математической обработкой полученных значений с помощью специально разработанного для прибора алгоритма.

Для получения результата измерений кониентрации по плотности потока лучей через проточную кювету разработан спечиальный алгоритм. Анализ площадей под кривыми зависимостей оптической плотности от длины волны показывает, что оптимальная длина волны для оценки характеристик концентрации нитратов находится в диапазоне $307-$ 309 нм. Выбор анализа трех длин волн вместо одной позволяет не реагировать на другие примеси и делает устройство более точным. Регистрачия солей $\mathrm{NO}_{3}$ в проточной воде осуществляется на компьютере с указанием даты и времени проведения исследования. Успешное сочетание современной элементной базы, а именно полупроводниковых ультрафиолетовых излучателей - светодиодов в спектральном диапазоне от 265 до 365 нм позволило уменьшить погрешности, связанные с загрязнителями воды типа фульвокислот, что мешало надежным измерениям. Тестирование на определение нитратов в воде позволило провести лабораторные испытания и подтвердить возможность промышленного использования. Предложенный способ реализуется путем измерения передачи световых пучков через специальную проточную кювету в диапазоне ультрафиолетовых излучений на трех длинах волн с математической обработкой значений, полученных для спечиально разработанного прибора. Настраивая прибор на допустимые примеси различных загрязнителей, мы впервые решаем задачу быстрого измерения нитратов непосредственно в трубопроводе и передачи данных на удаленный компьютер для обработки и хранения данных о состоянии воды в течение длительного времени.
\end{abstract}

Ключевье слова - нитрат-ионы; измерения нитратов; проточная вода; спектрофотометрия; УФ-излучения. 


\title{
A DEVICE FOR THE EXPERIMENTAL METERING OF NITRATES IN RUNNING WATER
}

\author{
O. Salivon, V. Zubchuk, candidate of technical sciences \\ associate professor of the department of BMI \\ okssalivon@gmail.com,grany@meta.ua \\ Faculty of Biomedical Engineering \\ National Technical University of Ukraine \\ "Igor Sikorsky Kyiv Polytechnic Institute" \\ Kyiv, Ukraine \\ V. Taranov, senior research fellow \\ lambit@ukr.net \\ A.V. Dumansky Institute of Colloid and Water Chemistry \\ National Academy of Sciences of Ukraine \\ Kyiv, Ukraine
}

\begin{abstract}
Methods and tools for determining the level of contamination in drinking water are important in various fields of human activity, because water quality is always important. Automated monitoring can improve the level of water quality control. The method and device for express metrics of nitrate levels in aqueous solutions based on the spectrophotometric method are developed. A distinctive feature of the development is the definition of contamination for flowing water without special preparation of solutions. The proposed method is implemented by measuring the transmission of light beams through a special flow cuvette in the ultraviolet range at three wavelengths and mathematical processing of the values obtained for a specially designed instrument for the algorithm.

To process the measured result, a special algorithm for transmitting radiation through a flow cuvette is developed. The analysis of the area under the curves of the dependence of the optical area on the wavelength suggests that the most optimal wavelength for evaluating the characteristics of the concentration of nitrates is in the region of 307-309 $\mathrm{nm}$. Choosing an analysis of three wavelengths instead of one can take into account other impurities and make the device more accurate. Registration of NO3 in running water is carried out on a computer, indicating the date and time of the study. The successful combination of a modern element base, namely semiconductor ultraviolet emitters - LEDs on a spectral plane from $265 \mathrm{~nm}$ to $365 \mathrm{~nm}$, allowed to overcome the obstacle associated with pollutants of water with fulvic acids, which prevented reliable measurements. Testing for determination of nitrates in water allowed to conduct laboratory tests and approach industrial use. The proposed method is realized by measuring the transmission of light beams through a patented flow cuvette in the range of ultraviolet radiation at three wavelengths and mathematical processing of the values obtained for a specially designed device. Setting up the device for admissible impurities of various pollutants, we first solve the problem of quickly measuring pollutants directly in the pipeline and transferring data to a remote computer for processing and storing data on the state of water for a long time.
\end{abstract}

Keywords - nitrate ions; measurement of nitrates; running water; spectrophotometry; UV radiation. 